\section{Aspectos espaciais do escorpionismo em Ponta Grossa, Paraná, Brasil}

\author{
Spatial distribution of scorpion stings in Ponta \\ Grossa, Paraná State, Brazil \\ Aspectos espaciales del escorpionismo en Ponta \\ Grossa, Paraná, Brasil
}

Bianca Mayara Kotviski 1 Ivana de Freitas Barbola 1

\author{
1 Universidade Estadual de \\ Ponta Grossa, Ponta Grossa, \\ Brasil. \\ Correspondência \\ B. M. Kotviski \\ Universidade Estadual de \\ Ponta Grossa. \\ Av. Carlos Cavalcanti 4748, \\ Ponta Grossa, PR 84030-900, \\ Brasil.
}

bianca_kotviski@hotmail.com

\begin{abstract}
Among all bites and stings by venomous animals, scorpion stings have increased significantly in urban areas all over Brazil. Considering that Ponta Grossa is the city in Paraná State with the highest incidence of reported scorpion stings, the current study aimed to assess trends in scorpion stings based on notification records and complaints from January 2008 to December 2010. The geographic coordinates of addresses with reported scorpion stings were collected, digitized, and spatialized, resulting in a cartogram of the georeferenced scorpion stings in the city. The incidence coefficients for this period showed that Ponta Grossa had 113.3 cases per 100,000 inhabitants, and that Colônia Dona Luiza, Neves, and Chapada were the neighborhoods with the highest rates. Investigation of determinants of scorpion stings used visual and statistical analysis, indicating wooded or green areas, water mains, and the sewer system as the main correlated variables.
\end{abstract}

Scorpions; Spatial Analysis; Accidents; Incidence

\section{Resumo}

Dentre os acidentes por animais peçonhentos, $o$ escorpionismo vem crescendo de forma significativa nas áreas urbanas de todo o país. Considerando que Ponta Grossa é o município com o maior número desse tipo de acidentes no Estado do Paraná, Brasil, o presente estudo teve por objetivo avaliar a situação do escorpionismo na cidade, com base na utilização de registros de acidentes e reclamações de ocorrência de escorpiões nas residências, entre janeiro de 2008 e dezembro de 2010. As coordenadas geográficas dos endereços em que houve notificações de acidentes foram coletadas, digitalizadas e espacializadas, resultando em um cartograma georreferenciado. Os coeficientes de incidência calculados para o período revelaram que Ponta Grossa apresentou 113,3 casos por 100 mil habitantes, sendo que os bairros Colônia Dona Luiza, Neves e Chapada foram os que apresentaram maior risco da ocorrência de acidentes. A investigação dos fatores determinantes desse agravo se deu por meio de análise visual e estatística, indicando áreas verdes, rede hidrográfica e rede de esgoto como as principais variáveis a ele associadas.

Escorpiões; Análise Espacial; Acidentes; Incidência 


\section{Introdução}

A importância dos acidentes por animais peçonhentos para a saúde pública pode ser expressa pelos mais de 100 mil acidentes e cerca de 200 óbitos registrados por ano. Dentre os diferentes tipos de envenenamento, o escorpionismo tem crescido de forma significativa no Brasil 1,2, correspondendo no ano de 2007 a 30\% das notificações, e superando em números absolutos os casos de ofidismo ${ }^{3}$.

É provável que além do aumento real do número de acidentes, a melhora no registro desse agravo, a partir da implantação da notificação dos acidentes escorpiônicos no país em 1988 4, também vem contribuindo para a elevação das taxas de incidência média, que foram de aproximadamente 17,7 casos/100 mil habitantes na última década 5 .

Acredita-se que o aumento do número de casos seja decorrente das modificações do ambiente natural pelo desmatamento e os diferentes usos do solo urbano pelo homem ${ }^{6}$, o que causa uma quebra na cadeia alimentar, acabando também com os locais de abrigo desses invertebrados. Com a escassez de recursos, esses animais passam a procurar alimento e abrigo em residências, terrenos baldios e áreas em construção 3,7,8. No entanto, muito pouco se sabe sobre quão longe os escorpiões se dispersam a partir de suas áreas natais ou se defendem ativamente um território (e se sim, quão grande é a área defendida) 6 .

Os acidentes causados por escorpiões constituem um problema de saúde pública e seu conhecimento clínico e epidemiológico é de alta relevância, sendo o georreferenciamento uma ferramenta importante para auxiliar nas políticas de saúde porque permite identificar as regiões mais suscetíveis, onde deverão ser desenvolvidas ações visando à prevenção e à adequação no atendimento ao paciente acidentado 9 .

Entre 2001 e 2010, aproximadamente 5.324 acidentes causados por escorpiões foram registrados usando-se o Sistema de Informação de Agravos de Notificação (SINAN) no Estado do Paraná, Brasil, sendo que a 3a Regional de Saúde do Paraná, que abrange 12 municípios, apresentou o maior número, 1.751 acidentes. Desse total, 1.209 (ou 69\%) ocorreram na cidade de Ponta Grossa, com o maior número de registros (168) ocorrido no ano de 2007.

Quanto ao encontro de escorpiões nos domicílios, nesse mesmo período, foram registradas 120 reclamações pela Gerência de Controle de Zoonoses da Prefeitura Municipal de Ponta Grossa.

Considerando que Ponta Grossa é o município com o maior número de acidentes escorpiô- nicos registrados no Estado do Paraná na última década, este estudo visa a avaliar a situação atual deste agravo na cidade, tendo como objetivos específicos: (1) espacializar todos os acidentes causados por escorpiões registrados no SINAN, no período de janeiro de 2008 a dezembro de 2010; (2) calcular o coeficiente de incidência para a cidade e os diferentes bairros; e (3) investigar as variáveis associadas a esse agravo.

\section{Material e métodos}

\section{Área de estudo}

Localizada no Segundo Planalto Paranaense e na Mesorregião Centro-oriental do estado (Figura 1), Ponta Grossa apresenta uma população de aproximadamente 311.611 habitantes (Instituto Brasileiro de Geografia e Estatística. População da Cidade de Ponta Grossa. http://www.ibge.gov. $\mathrm{br} /$ cidadesat/topwindow.htm? 1 , acessado em 08/Set/2011) e é considerada a cidade polo de uma das regiões mais populosas do estado, os Campos Gerais do Paraná. O clima é do tipo Cfb - Subtropical Úmido Mesotérmico, com temperatura média anual entre $17^{\circ} \mathrm{C}$ e $18^{\circ} \mathrm{C}$ e regime pluviométrico bastante variado, com maior concentração de chuva nos meses do verão. Devido ao seu zoneamento geomorfológico apresenta um relevo bastante acidentado, o que facilita o surgimento de vales profundos e consequentemente a exposição do lençol freático, constituindo uma característica peculiar e uma hidrografia bastante abundante. Na área compreendida como urbana podem-se contabilizar 12 bacias hidrográficas e cinco parques municipais, além de diversas áreas e zonas verdes 10 .

\section{Coleta e análise de dados}

A fim de cumprir os objetivos propostos neste trabalho, foram utilizados dados a respeito dos acidentes e reclamações de ocorrência de escorpiões, no período de janeiro de 2008 a dezembro de 2010, atualizados até fevereiro de 2011.

Os 353 registros referentes aos acidentes foram obtidos nas Fichas de Investigação de Acidentes por Animais Peçonhentos do SINAN, sendo fornecidos pela Secretaria de Estado da Saúde do Paraná (SESA/PR). Desses, 148 correspondem aos acidentes notificados no ano de 2008, $93 \mathrm{em}$ 2009 e 112 em 2010. Do total de registros, 50 foram previamente descartados devido à inexistência do nome da rua nos mapas da cidade (39) ou à falta de número (11) no endereço informado, sendo esperado, portanto, o encontro de 303 endereços válidos. 


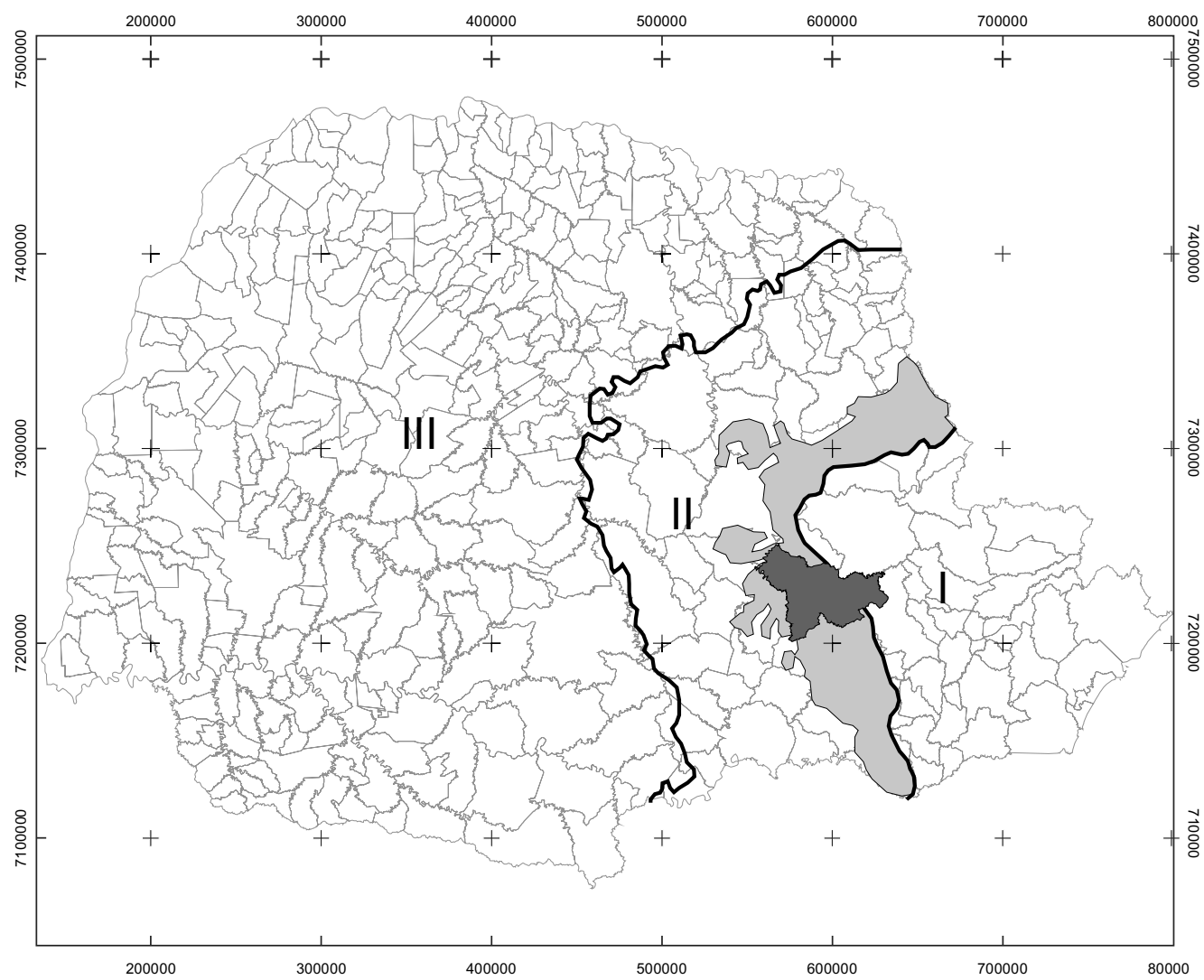

30.000030 .000 metros

Sistema de Coordenadas o UTM

Datum Horizontal o SAD69
1 Primeiro planalto

II Segundo planalto

III Terceiro planalto

Ponta Grossa

Campos Gerais do Paraná
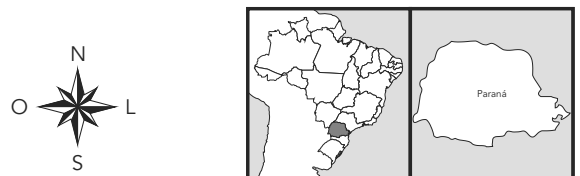
Bairros do perímetro urbano de Ponta Grossa, Paraná, Brasil.
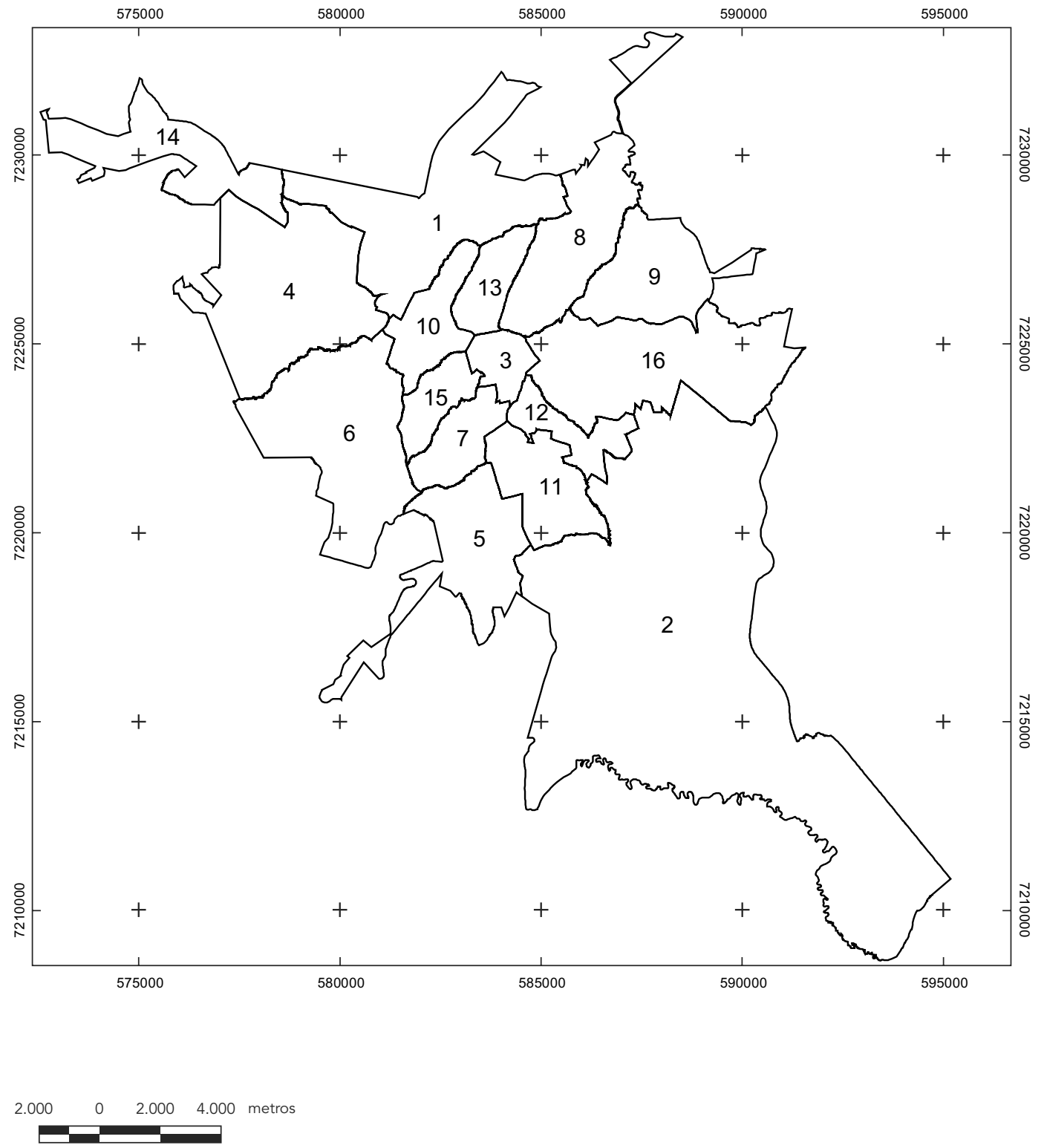

Sistema de Coordenadas o UTM Datum Horizontal o SAD69

Bairros de Ponta Grossa

\begin{tabular}{|c|c|c|c|}
\hline 1 & Boa Vista & 9 & Neves \\
\hline 2 & Cará-Cará & 10 & Nova Rússia \\
\hline 3 & Centro & 11 & Oficinas \\
\hline 4 & Chapada & 12 & Olarias \\
\hline 5 & Colônia Dona Luiza & 13 & Órfãs \\
\hline 6 & Contorno & 14 & Piriquitos \\
\hline 7 & Estrela & 15 & Ronda \\
\hline 8 & Jardim Carvalho & 16 & Uvaranas \\
\hline
\end{tabular}


positioningsystem (GPS) (marca GARMIN, modelo eTrexLegend). Posteriormente, foram digitalizadas e usando-se o programa ArcGIS (versão 9.3. http://www.esri.com/software/arcgis/index. html) foram espacializadas.

A fim de determinar o risco da ocorrência de acidentes causados por escorpiões para toda a população da cidade e de cada um dos bairros, foi calculado o coeficiente de incidência (CI), sendo o $\mathrm{CI}=$ número de casos ocorrentes de uma doença em determinada comunidade em certo período de tempo/número de pessoas expostas ao risco de adquirir a doença no referido período x 10n 11. O número de habitantes de cada bairro corresponde aos dados do Censo Demográfico de 2010 por serem mais próximos do período analisado.

Para visualização geral da intensidade do escorpionismo em Ponta Grossa, com base no comportamento de padrões de pontos (neste caso, os endereços dos registros de acidentes), foi gerado um mapa (também no programa ArcGIS) utilizando-se a técnica de kernel. A estimativa kernel é uma técnica de interpolação exploratória, que gera uma superfície de densidade para a identificação visual de áreas com uma concentração de eventos que indica de alguma forma a aglomeração em uma distribuição espacial 12 .

Áreas consideradas foco de ocorrência de escorpiões devido ao favorecimento ambiental para sua proliferação, como margens de rios, córregos e riachos, cemitérios, linhas férreas, terrenos baldios, áreas com esgoto a céu aberto, entre outras ${ }^{3}$, foram utilizadas para a investigação das possíveis causas deste agravo. Por meio de análise visual dos mapas do Plano Diretor do município e dos programas WEBGIS (Sistema de Informações Geográficas via WEB, http://geo. pg.pr.gov.br/portal/WEBGIS_SIT), Google Earth (https://www.google.com/intl/pt-BR/earth/in dex.html) e Google Maps (https://maps.google. com.br/), os fatores descritos na literatura como relacionados ao escorpionismo e observados em campo foram analisados para as vilas com o maior número de acidentes em cada um dos bairros.

Para os fatores mais frequentes, quando possível, aplicou-se o teste de associação do qui-quadrado $\left(\chi^{2}\right)$ e o coeficiente V de Cramér ${ }^{13}$, sendo que os dados foram obtidos por meio da sobreposição das coordenadas geográficas em mapas, imagens e vetores georreferenciados referentes aos fatores ambientais, disponíveis no site da Prefeitura Municipal de Ponta Grossa, usando-se o programa ArcGIS (versão 9.3). A tabela de contingência 16X2 foi elaborada considerando-se os bairros do município e a presença ou ausência do fator associado ao escorpionismo. Já as tabelas
16X3 representaram os bairros e a distância (em metros) entre os locais dos acidentes e o fator a ser analisado.

Existem poucas informações sobre a capacidade de deslocamento dos escorpiões e seu alcance a áreas domiciliares, porém, sabe-se que algumas espécies oportunistas (ou generalistas), tais como alguns membros dos gêneros Centruroides, Tityus e Isometrus invadem ambientes urbanos, possuem grandes densidades populacionais e alta capacidade de dispersão 2,6,14,15,16. Assim, no presente estudo foram arbitradas categorias de distância entre os locais de ocorrência de acidentes e alguns dos fatores ambientais possivelmente associados, considerando-se próximos àqueles locais a distância de até $50 \mathrm{~m}$ do fator a ser analisado, intermediários entre $51 \mathrm{e}$ $100 \mathrm{~m}$ e distantes os com mais de $100 \mathrm{~m}$, baseando-se em observações de Mineo et al. 17 .

Este trabalho foi analisado e aprovado pelo Comitê de Ética em Pesquisa Envolvendo Seres Humanos (COEP), da Universidade Estadual de Ponta Grossa, pelo parecer de no 98/2011 e o protocolo no 14729/11.

\section{Resultados e discussão}

No período investigado, foram notificados 353 acidentes por escorpião em Ponta Grossa. Se levarmos em conta o número de habitantes da cidade (311.611) e todos os acidentes notificados no período (353), mesmo sem a confirmação de alguns endereços, chega-se a um CI de 113,3 casos por 100 mil habitantes, sendo 47,5 casos / 100 mil habitantes em 2008, 29,8/100 mil em 2009 e 35,9/100 mil em 2010. Os valores encontrados superam de forma preocupante a incidência de casos de acidentes por escorpiões nesse mesmo período para o país (que foi de 21,5; 25,7 e 26,3 acidentes/100 mil habitantes) e também para o Paraná $(7,0 ; 6,6$ e 7,5) 5 .

$\mathrm{Na}$ comparação entre os bairros foram desconsiderados os registros com inexistência do nome da rua nos mapas da cidade (39) (Tabela 1).

Os bairros que apresentaram as mais elevadas taxas de incidência acumulada para o período foram Colônia Dona Luiza e Neves, ambos com $\mathrm{CI}=16,2$ casos por 10 mil habitantes. Já no ano de 2008, o bairro que apresentou o maior risco da ocorrência de acidentes foi o Colônia Dona Luiza, com CI = 9,6 casos $/ 10$ mil habitantes; em 2009, o Chapada, com CI = 5,2 casos $/ 10$ mil habitantes e em 2010, o maior valor de CI (6,8 casos / 10 mil habitantes) correspondeu ao bairro Neves. Essa variação indica que o escorpionismo está se dispersando consideravelmente, pois em um curto período três bairros diferentes e distantes 
Número de acidentes causados por escorpiões na cidade de Ponta Grossa, Paraná, Brasil e respectivos valores do coeficiente de incidência (Cl) para os anos de 2008, 2009 e 2010 e total acumulado.

\begin{tabular}{|c|c|c|c|c|c|c|c|c|c|}
\hline \multirow[t]{2}{*}{ Bairros } & \multicolumn{4}{|c|}{ Acidentes } & \multicolumn{4}{|c|}{$\mathrm{Cl}\left(10^{4}\right)$} & \multirow[t]{2}{*}{ Habitantes } \\
\hline & 2008 & 2009 & 2010 & Total & 2008 & 2009 & 2010 & Total & \\
\hline Boa Vista & 4 & 7 & 3 & 14 & 1,6 & 2,8 & 1,2 & 5,6 & 24.968 \\
\hline Cará-Cará & 9 & 7 & 11 & 27 & 3,6 & 2,8 & 4,4 & 10,9 & 24.779 \\
\hline Centro & 2 & 2 & 1 & 5 & 1,6 & 1,6 & 0,8 & 4,1 & 12.325 \\
\hline Chapada & 13 & 12 & 12 & 37 & 5,6 & 5,2 & 5,2 & 16,0 & 23.166 \\
\hline Colônia Dona Luiza & 16 & 3 & 8 & 27 & 9,6 & 1,8 & 4,8 & 16,2 & 16.639 \\
\hline Contorno & 5 & 3 & 7 & 15 & 1,8 & 1,1 & 2,5 & 5,3 & 28.386 \\
\hline Estrela & 3 & 0 & 1 & 4 & 4,0 & 0,0 & 1,3 & 5,3 & 7.548 \\
\hline Jardim Carvalho & 7 & 9 & 9 & 25 & 3,1 & 4,0 & 4,0 & 11,2 & 22.393 \\
\hline Neves & 13 & 8 & 15 & 36 & 5,9 & 3,6 & 6,8 & 16,2 & 22.211 \\
\hline Nova Rússia & 7 & 9 & 8 & 24 & 3,6 & 4,6 & 4,1 & 12,2 & 19.656 \\
\hline Oficinas & 10 & 5 & 2 & 17 & 4,9 & 2,4 & 1,0 & 8,3 & 20.414 \\
\hline Olarias & 3 & 1 & 4 & 8 & 3,5 & 1,2 & 4,7 & 9,4 & 8.545 \\
\hline Órfãs & 12 & 3 & 2 & 17 & 9,2 & 2,3 & 1,5 & 13,0 & 13.107 \\
\hline Piriquitos & 2 & 0 & 3 & 5 & 3,7 & 0,0 & 5,5 & 9,2 & 5.417 \\
\hline Ronda & 7 & 3 & 3 & 13 & 7,6 & 3,3 & 3,3 & 14,1 & 9.229 \\
\hline Uvaranas & 22 & 9 & 9 & 40 & 4,9 & 2,0 & 2,0 & 9,0 & 44.450 \\
\hline Total considerado & 135 & 81 & 98 & 314 & & & & & \\
\hline Endereço inexistente & 13 & 12 & 14 & 39 & & & & & \\
\hline Total real & 148 & 93 & 112 & 353 & & & & & 303.233 \\
\hline
\end{tabular}

Fonte: Divisão de Vigilância de Zoonoses e Intoxicações, Departamento de Vigilância Ambiental em Saúde, Superintendência de Vigilância em Saúde, Secretaria de Estado da Saúde do Paraná. Instituto Brasileiro de Geografia e Estatística (http://www.ibge.gov.br).

entre si estiveram mais expostos ao risco de sofrer acidentes.

A maioria dos bairros manteve o número de acidentes mais ou menos constante ao longo do período avaliado. Já os bairros Cará-Cará, Contorno, Jardim Carvalho, Neves, Nova Rússia e Olarias demonstram uma leve tendência ao aumento do número de casos, o que pode ser explicado pela própria expansão urbana, com o surgimento de novas vilas e conjuntos habitacionais. A heterogeneidade do ambiente urbano traduzida em diferenças no microclima e na disponibilidade de presas e outros recursos, pode influenciar na abundância e na distribuição dos escorpiões 6, sendo, portanto, a ampla ocorrência dos acidentes nos bairros um indicativo da disseminação e colonização dos escorpiões na cidade 18 .

Segundo os dados fornecidos pela Gerência de Controle de Zoonoses, as localidades predominantes em relação à reclamação da ocorrência de escorpiões foram o bairro Jardim Carvalho e a Vila Liane (sendo esta vila pertencente ao bairro Órfãs), em 2008; a Vila Conjunto Habitacional Verona (pertencente ao bairro Contorno) e a Vila
Conjunto Habitacional Santa Marta (pertencente ao bairro Colônia Dona Luiza), em 2009; e o bairro Uvaranas, em 2010. Nota-se que essas localidades não estiveram relacionadas nem aos bairros com o maior número de acidentes, nem com os que apresentaram os maiores coeficientes de incidência, no mesmo período. Isso pode ser explicado devido ao reduzido número de reclamações quando comparado às notificações de acidentes, talvez ocasionado pelo desconhecimento da comunidade sobre a existência de um setor responsável por receber essas reclamações, pela dificuldade de acesso à localidade e/ou aparelhos telefônicos para efetuar a reclamação, pela desconfiança da população em relação ao retorno do poder público com ações efetivas ou mesmo pela pouca importância que o escorpião representa para algumas pessoas como risco à saúde 8 .

Dos 303 endereços esperados para análise, 40 não existiam ou não foram encontrados, totalizando assim 263 coordenadas geográficas coletadas, ou seja, um georreferenciamento com $86,8 \%$ de aproveitamento dos registros que continham 
endereços válidos. Esse valor é considerado adequado quando comparado com o de instituições públicas que utilizam a distribuição espacial com mais ou menos $85 \%$ de aproveitamento 9,19,20.

A espacialização dos registros de acidentes referentes a cada um dos anos de estudo resultou em um cartograma georreferenciado, sendo 117 registros correspondentes ao ano de 2008, 61 ao de 2009 e 85 ao de 2010 (Figura 3). O cartograma permite observar que a distribuição dos casos expandiu em torno dos locais onde já haviam ocorrido acidentes. Portanto, é provável que os escorpiões já habitassem essas áreas e com o aumento de contingentes humanos, decorrentes da urbanização que se processa, os casos de acidentes têm maior ocorrência nesses locais 8 .

Para a área investigada, os fatores que possivelmente estariam relacionados ao escorpionismo, segundo a análise visual da distribuição espacial dos acidentes nas vilas com maior número de registros em cada um dos bairros, foram (em ordem decrescente): rede hidrográfica, ocupações irregulares, áreas verdes, terrenos baldios, madeireiras, rede de esgoto, vegetação/uso do solo, rodovia, serralherias, ferrovias, edificações e cemitérios.

Entre os seis fatores mais frequentes foi possível analisar a influência da proximidade da rede hidrográfica (cursos e arroios), das ocupações irregulares, das áreas verdes e da presença ou ausência de rede de esgoto.

Os dados da rede hidrográfica (Figura 4) demonstraram que $17,5 \%$ (46) dos casos ocorreram a uma distância próxima, 17,5\% (46) intermediária e $65,0 \%$ (171) distante dos cursos e arroios. Os locais de maior concentração de acidentes que estavam associados à rede hidrográfica em cada bairro pertencem a sete bacias hidrográficas: Pilão de Pedra, Lageado Grande, Ronda, Olarias, Arroio Grande, Taquari e Santa Tereza 10, sendo que as duas primeiras são comuns a mais de dois bairros. Vale ressaltar que esses corpos d'água são, em sua maioria, poluídos pelo acúmulo de lixo, esgoto e entulhos depositados pela população do entorno.

Quanto à proximidade dos locais de acidentes com as áreas de ocupações irregulares (Figura 5), observa-se que $21,7 \%$ (57) estavam a uma distância próxima, 10,3\% (27) intermediária e 68,1\% (179) distante. As atuais formas de ocupação urbana em Ponta Grossa são resultantes do rápido aumento populacional e da incapacidade do poder público em resolver os problemas decorrentes deste. E, em consequência, áreas de preservação permanente pertencentes a encostas, fundos de vale, nascentes e áreas alagadiças foram ocupadas irregularmente 10. Como apontam Nodari et al. 7, a ocupação irregular de áreas contribui para as precárias condições de moradia, ocasionando a proliferação dos aracnídeos e, por consequência, a elevação dos riscos de acidentes.

A presença de áreas verdes, incluindo os parques municipais, na zona urbana do município (Figura 6) demonstrou que 8\% (21) dos casos ocorreram a uma distância próxima destas, 6,5\% (17) intermediária e 85,6\% (225) distante. Ponta Grossa possui um número insignificante de áreas verdes e a manutenção dos parques existentes é deficiente, mesmo com a existência de áreas nobres com potencial para a criação de áreas protegidas 10. Entretanto, como essas áreas são habitats naturais dos aracnídeos, eles acabam migrando para as residências quando a disponibilidade de recursos diminui devido à remoção da vegetação e ocupação humana ${ }^{3,7}$.

Em 2006, o sistema de esgotamento sanitário de Ponta Grossa teve seu nível de atendimento considerado deficiente, pois atendia apenas $52 \%$ da população ${ }^{10}$. De acordo com os dados de 2008 nota-se que o problema se mantém, sendo as residências da periferia da cidade as mais desfavorecidas (Figura 7). A ausência de rede de esgoto correspondeu a 23,6\% (62) dos endereços válidos e a presença a $76,4 \%$ (201), sendo que a ausência de saneamento está, em grande parte, associada a áreas com esgoto a céu aberto. A elevada frequência de acidentes mesmo em áreas com saneamento básico deve estar relacionada ao fato de que os escorpiões vivem em galerias de esgoto, locais com abundância de baratas, o seu principal alimento $3,4,9$, podendo chegar às moradias através das tubulações.

A análise estatística foi aplicada para as quatro variáveis descritas acima. O teste do quiquadrado indicou que existe associação entre os acidentes causados por escorpiões e as áreas verdes $\left(\chi^{2}=64,37 ; p=0,0003\right)$, a rede hidrográfica $\left(\chi^{2}=47,30 ; p=0,0232\right)$ e a rede de esgoto $\left(\chi^{2}=33,48 ; p=0,0004\right)$ em Ponta Grossa. O coeficiente $\mathrm{V}$ de Cramér revelou que o maior grau de associação ocorreu entre os acidentes e a variável rede de esgoto $(\mathrm{V}=0,3568)$, seguida da área verde $(\mathrm{V}=0,3498)$ e da rede hidrográfica ( $\mathrm{V}=0,2999)$, porém, indicou pouca associação entre todas as variáveis em análise, tendo em vista que este índice assume valores que variam entre zero (0) e um (1).

Ao se aplicar a técnica de kernel no mapa contendo os registros de acidentes ocorridos entre 2008 e 2010 (Figura 8), verifica-se a maior intensidade de agravos nos limítrofes entre os bairros Neves, Jardim Carvalho e Uvaranas. Outros pontos de alta concentração de acidentes são observados nos limítrofes dos bairros Nova Rússia e Órfãs e na porção leste do bairro Colônia Dona Luiza. Pela análise visual, os pontos 
Registros de acidentes causados por escorpiões no Município de Ponta Grossa, Paraná, Brasil.

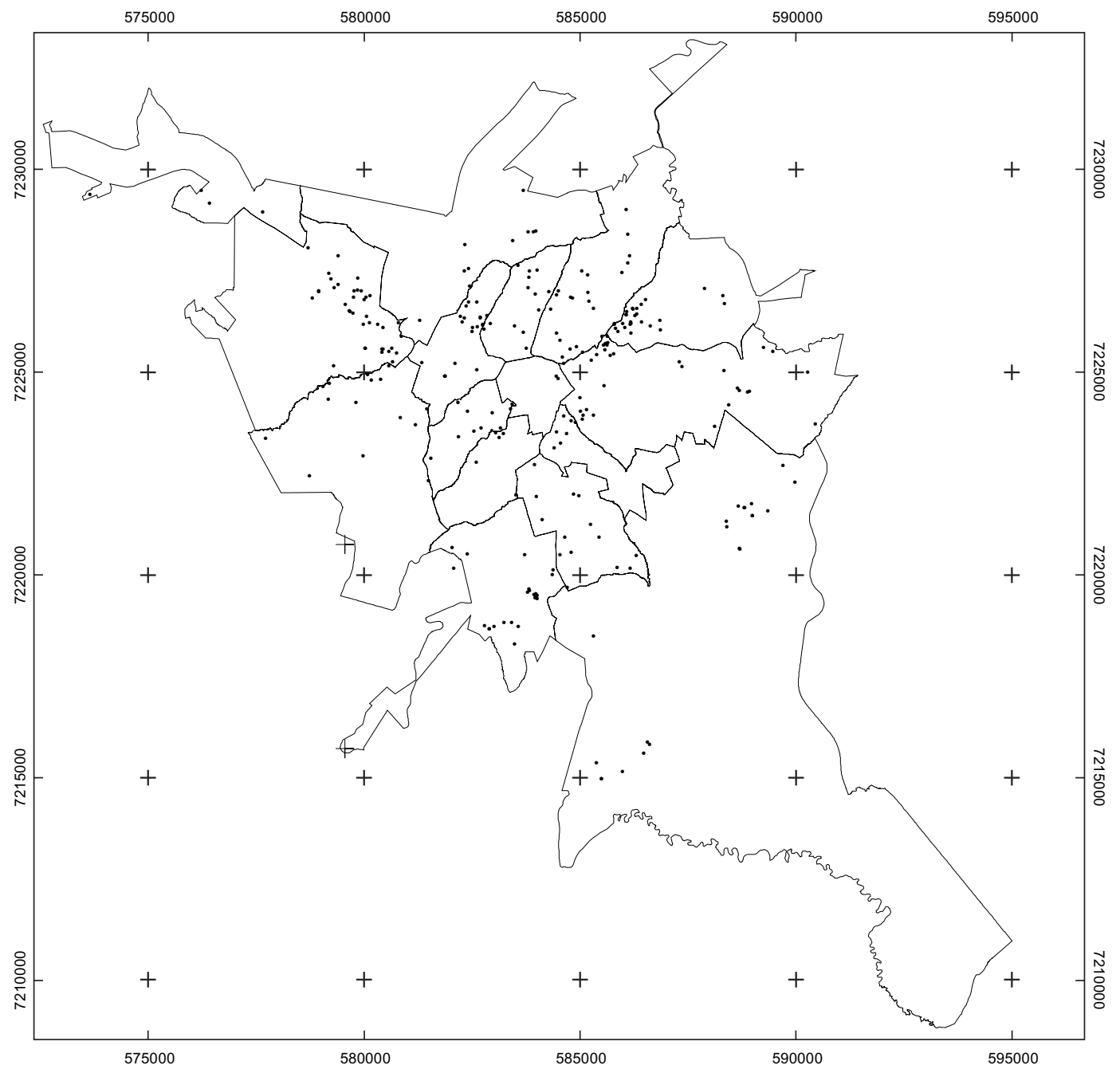

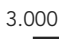

0

3.000

6.000 metros

Sistema de Coordenadas o UTM

Datum Horizontal o SAD69
- Acidentes (2008-2010)

- Bairros
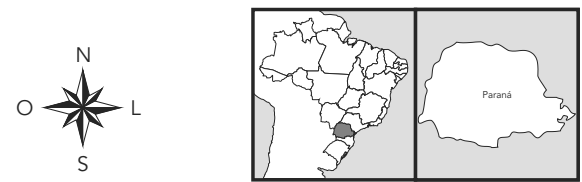
Relação entre os acidentes causados por escorpiões e a rede hidrográfica no Município de Ponta Grossa, Paraná, Brasil.

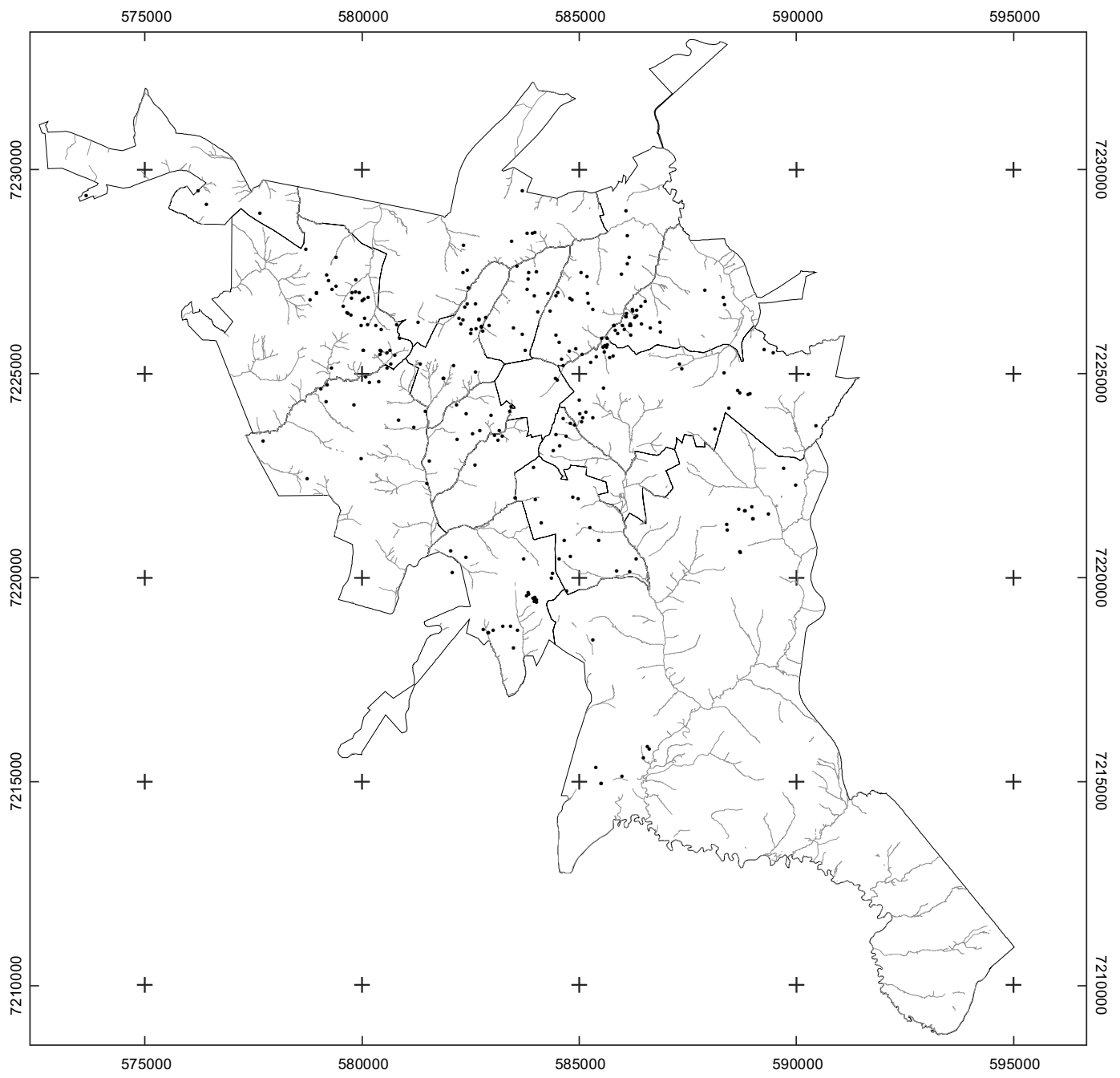

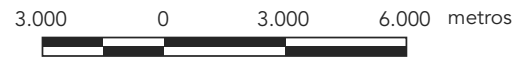

Sistema de Coordenadas o UTM Datum Horizontal o SAD69
- Acidentes (2008-2010)

$\checkmark$ Hidrografia

- Bairros
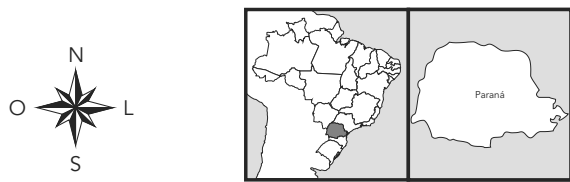
Relação entre os acidentes causados por escorpiões e as áreas de ocupação irregular no Município de Ponta Grossa, Paraná, Brasil.

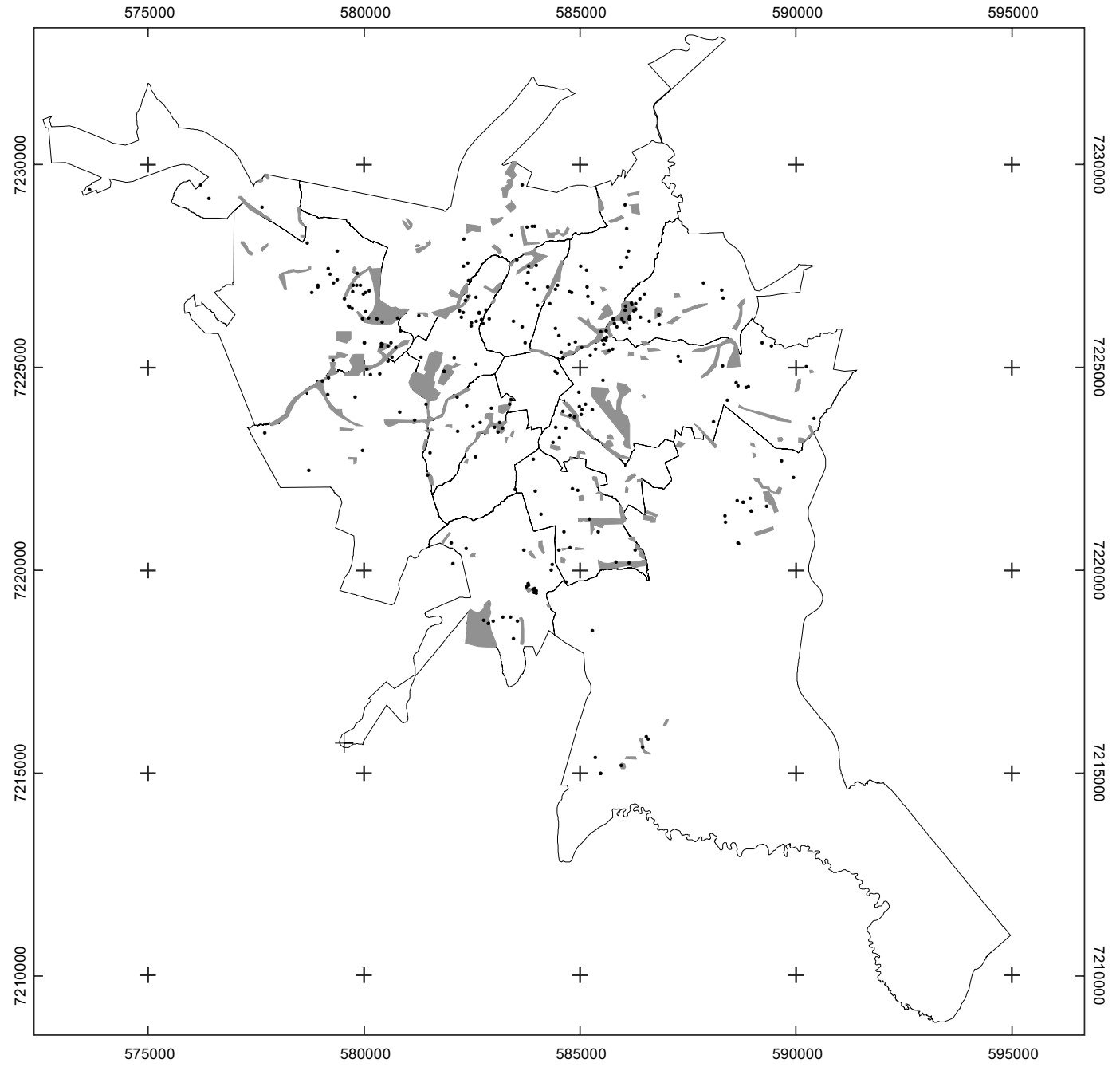

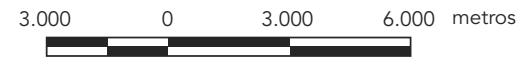

Sistema de Coordenadas o UTM

Datum Horizontal o SAD69
- Acidentes (2008-2010)

Áreas de ocupação irregular - Bairros 
Relação entre os acidentes causados por escorpiões e as áreas verdes no Município de Ponta Grossa, Paraná, Brasil.

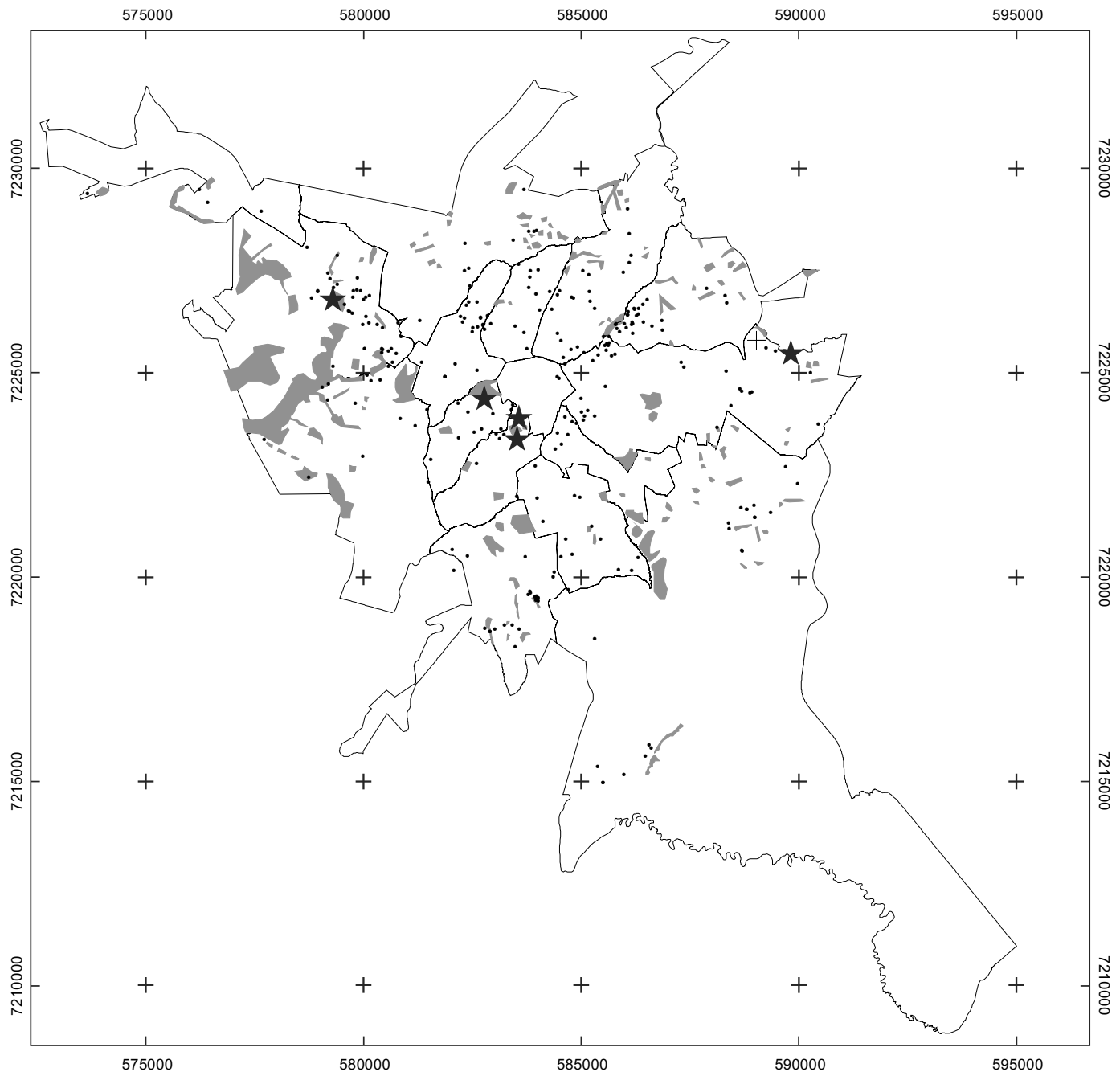

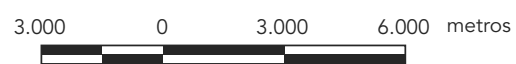

Sistema de Coordenadas o UTM Datum Horizontal o SAD69
- Acidentes (2008-2010)

$\star$ Parques Municipais

Áreas verdes

- Bairros

$0 \frac{k_{s}^{N}}{r_{1}}$

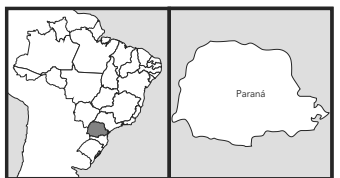


Figura 7

Relação entre os acidentes causados por escorpiões e a rede de esgoto no Município de Ponta Grossa, Paraná, Brasil.
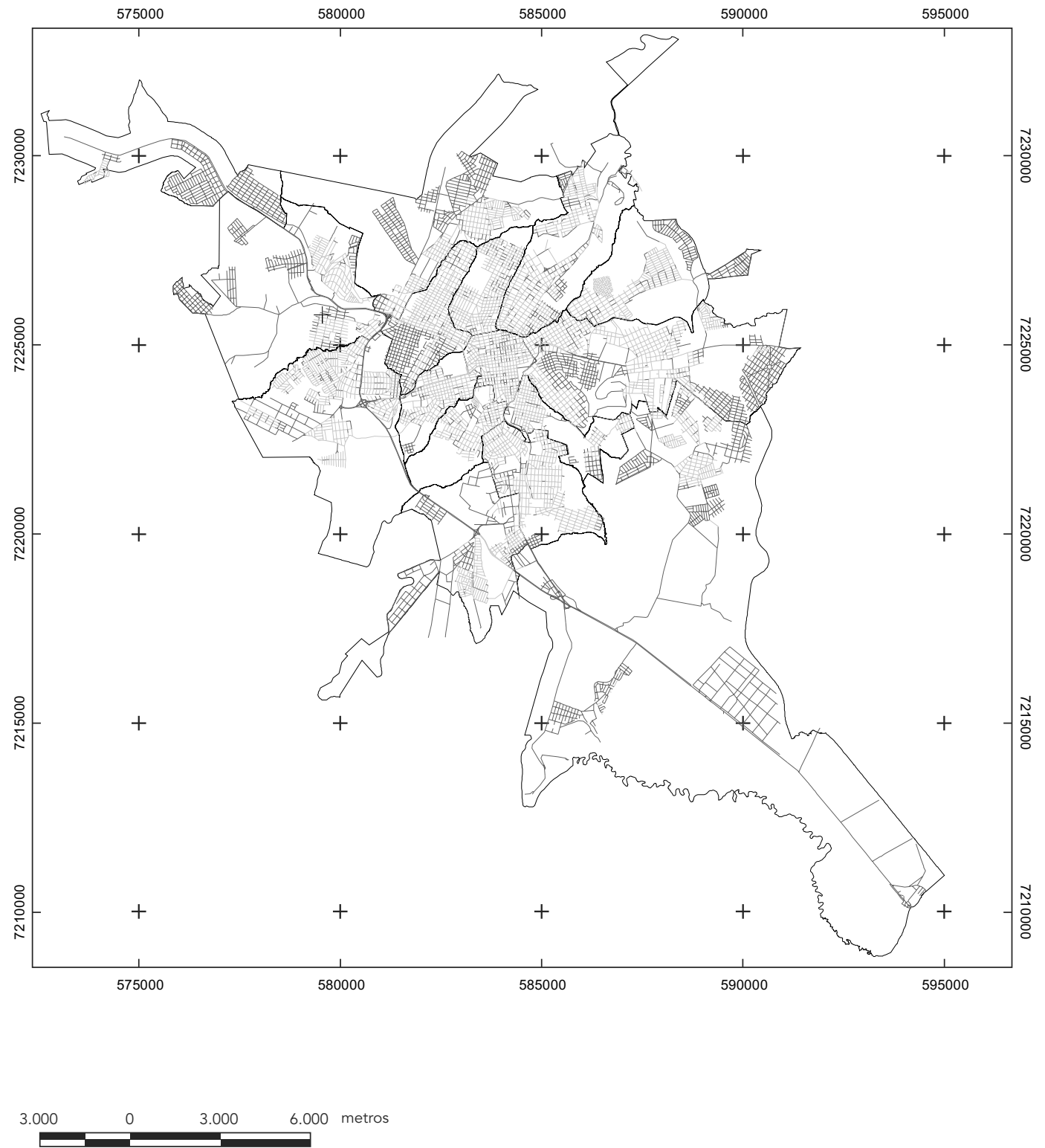

Sistema de Coordenadas o UTM Datum Horizontal o SAD69

Sem rede de esgoto

Com rede de esgoto

- Acidentes (2008-2010)

- Bairros
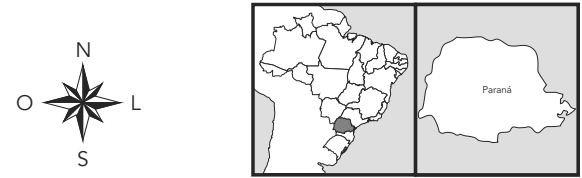
Distribuição e intensidade dos acidentes causados por escorpiões no Município de Ponta Grossa, Paraná, Brasil, entre 2008 e 2010, segundo a técnica de Kernel.

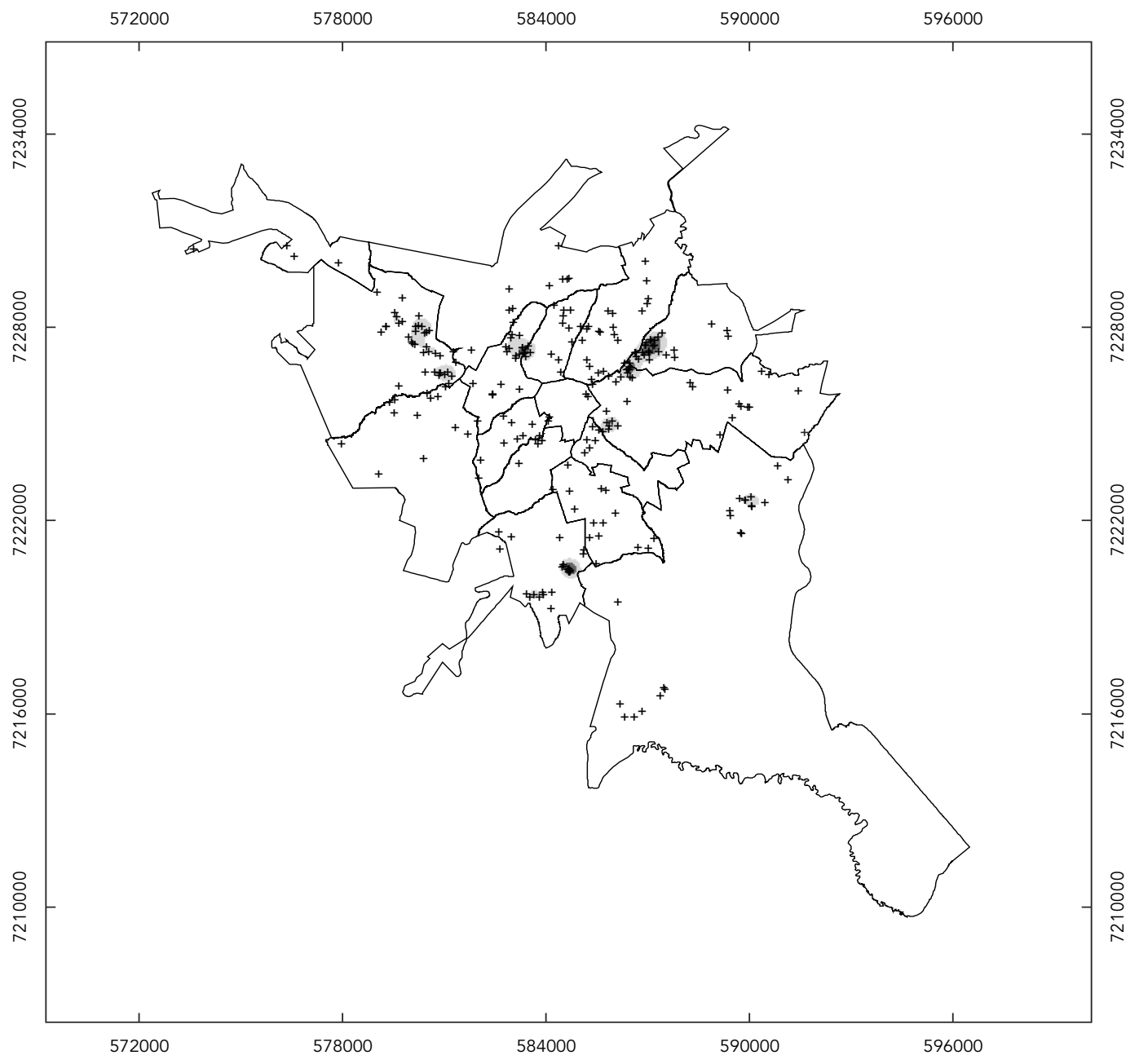

\begin{tabular}{l}
$0 \quad 2.000 \quad 4.000$ \\
\hline
\end{tabular}

Sistema de Coordenadas o UTM Datum o SAD69

Org. ROSA, J.Z., 2012

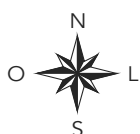

+ Pontos de maior concentração de acidentes

Concentração de Acidentes

$\square$ Baixa

$\square$ Média

$\square$ Alta 
de maior concentração de acidentes estão mais próximos de áreas com rede de esgoto e de cursos d'água e arroios, semelhante ao que foi observado na análise estatística. Os locais com alta intensidade de acidentes estiveram relacionados aos bairros onde houve reclamações e tendência ao aumento do número de casos.

Os resultados obtidos sugerem que a causa dos acidentes em determinados locais não é decorrente de um único fator, mas sim da interação de diversos deles, sendo isto reforçado pelo fato de que muitos dos cursos e arroios de Ponta Grossa estão poluídos por esgoto doméstico e de que as áreas verdes da cidade recebem pouca manutenção e apresentam acúmulo de lixo e entulhos, condições que propiciam ainda mais a proliferação de aracnídeos 25 . De acordo com Nunes et al. 8 e McIntyre 6 , a distribuição espacial dos acidentes escorpiônicos está associada à existência de áreas heterogêneas, com padrões diferenciados de ocorrência de casos, ou seja, regiões com estruturas de causalidades distintas que determinam formas específicas de morbidade, em relação a esse agravo.

Pesquisas abordando aspectos fundamentais sobre a ecologia de escorpiões, bem como as distâncias potenciais de dispersão ainda são escassas 6,22, o que dificulta uma análise mais precisa da capacidade destes artrópodes alcançarem e colonizarem ambientes domésticos. Porém, observações preliminares indicam que em condições naturais a espécie Tityus serrulatus Lutz \& Mello, 1922, é capaz de se locomover por longas distâncias durante uma mesma noite, podendo ir além de 30 metros 17 , o que também foi observado por Kaltsas \& Mylonas 23 em machos da espécie Mesobuthus gibbosus (Brullé, 1832). No presente estudo, a maioria dos acidentes ocorreu em pontos considerados distantes (acima de 100m) dos cursos d'água, das áreas verdes e das ocupações irregulares, podendo indicar que os escorpiões têm uma capacidade de dispersão pelo ambiente bem maior do que a descrita na literatura. Isso pode ser explicado pelo fato deles se deslocarem ativamente em busca de alimento e abrigo, e dos machos percorrerem longas distâncias em busca de fêmeas para acasalar 23. Destaca-se ainda a possibilidade de dispersão passiva dos animais por meio de cargas de materiais onde eles se encontram como tijolos, telhas, madeiras e outros materiais de construção ${ }^{3}$.
Para diversos autores, a distribuição diferenciada dos acidentes escorpiônicos no contexto urbano está associada a aspectos geográficos, envolvendo clima, relevo, tipo de vegetação e solo, à forma de ocupação dos espaços urbanos, bem como à distribuição e organização de serviços e equipamentos de saneamento básico. Assim, além das características ambientais que favorecem o aparecimento de escorpiões, a incidência de casos em comunidades de periferias urbanas de baixo nível socioeconômico e sanitário é maior 2,6,8,16,24.

O georreferenciamento do escorpionismo em Ponta Grossa permitiu identificar as localidades mais atingidas, constituindo uma importante ferramenta para subsidiar programas de controle de infestação ambiental. Acredita-se que desta forma o poder público poderá analisar a real situação do escorpionismo na cidade e priorizar esforços visando à diminuição do número de acidentes.

\section{Conclusão}

A espacialização dos registros de acidentes causados por escorpiões permitiu evidenciar que o escorpionismo está amplamente distribuído em Ponta Grossa, sendo que existe uma tendência de expansão destes em torno dos locais onde já ocorreram acidentes.

A incidência dos casos na cidade esteve bem acima das encontradas para o estado e o país, e as calculadas para os bairros demonstraram que Colônia Dona Luiza, Chapada e Neves foram os que apresentaram os maiores riscos da ocorrência de acidentes em 2008, 2009 e 2010, respectivamente.

As variáveis ambientais associadas a esse agravo foram além da proximidade com as áreas verdes, que são habitats naturais desses aracnídeos; a rede de esgoto, cujas galerias são moradias dos escorpiões devido à abundância de baratas; e os cursos d'água e arroios, poluídos em sua maioria.

As informações obtidas nesta pesquisa poderão servir de subsídios aos órgãos responsáveis, para futuras intervenções que visem ao combate e à prevenção de acidentes por escorpiões na região. 


\section{Resumen}

Entre los accidentes ocasionados por animales venenosos, el escorpionismo ha estado creciendo de forma significativa en las áreas urbanas de todo el país. Teniendo en consideración que Ponta Grossa es el municipio con el mayor número de accidentes de este tipo, registrados en el estado de Paraná, Brasil, el presente estudio tuvo por objetivo evaluar la situación del escorpionismo en la ciudad, a partir de la utilización de registros de accidentes y denuncias por la aparición de escorpiones en residencias, entre enero de 2008 y diciembre de 2010. Las coordenadas geográficas de las direcciones en las que hubo notificaciones de accidentes se recogieron, digitalizaron y espacializaron, teniendo como resultado un cartograma georreferenciado. Los coeficientes de incidencia calculados para el período revelaron que Ponta Grossa presentó 113,3 casos por 100 mil habitantes, cuyos barrios Colonia Dona Luiza, Neves y Chapada fueron los que presentaron mayor riesgo de ocurrencia de accidentes. La investigación de los factores determinantes de este resultado se produjo por medio de análisis visual y estadístico, indicando áreas verdes, red hidrográfica y red de alcantarillado como las principales variables a él asociadas.

Escorpiones; Análisis Espacial; Acidentes;

Incidencia

\section{Colaboradores}

B. M. Kotviski contribuiu na concepção e planejamento do trabalho, na análise e interpretação dos dados, na redação do artigo e aprovação da versão final do manuscrito. I. F. Barbola contribuiu na concepção e interpretação dos dados, na redação do artigo, revisão crítica do conteúdo e aprovação da versão final do manuscrito.

\section{Agradecimentos}

As autoras agradecem à Divisão de Vigilância de Zoonoses e Intoxicação da Secretaria de Estado da Saúde do Paraná e à Gerência de Controle de Zoonoses da Prefeitura Municipal de Ponta Grossa, pela disponibilização de informações que auxiliaram na concretização deste estudo; à Profa. Dra. Maysa de Lima Leite, pelas sugestões de análises estatísticas; à geógrafa Me. Ingrid Aparecida Gomes, pela contribuição na produção das ilustrações e à Profa. Dra. Selma Regina Aranha Ribeiro e ao acadêmico Joel Zubek Rosa, pela organização do mapa.

\section{Referências}

1. Lourenco WR, Cloudsley-Thompson JL, Cuellar O, Von Eickstedt VRD, Barraviera B, Knox MB. The evolution of scorpionism in Brazil in recent years. J Venom Anim Toxins 1996; 2:121-34.

2. Eickstedt VRD, Ribeiro LA, Candido DM, Albuquerque MT, Jorge MT. Evolution of scorpionism by Tityus bahiensis (Perty) and Tityus serrulatus Lutz and Mello and geographical distribution of the two species in the state of São Paulo - Brazil. J Venom Anim Toxins 1996; 2:92-105.

3. Departamento de Vigilância Epidemiológica, Secretaria de Vigilância em Saúde, Ministério da Saúde. Manual de controle de escorpiões. Brasília: Ministério da Saúde; 2009.
4. Fundação Nacional de Saúde. Manual de diagnóstico e tratamento de acidentes por animais peçonhentos. 2a Ed. Brasília: Fundação Nacional de Saúde; 2001.

5. Ministério da Saúde. Incidência (100.000 hab) de casos de acidentes por escorpiões. Brasil, Grandes Regiões e Unidades Federadas. 2000 a 2010. http://portal.saude.gov.br/portal/arquivos/pdf/ tabela10_inci_casos_escorpiao_01_04_2011.pdf (acessado em 10/Out/2011).

6. McIntyre NE. Influences of urban land use on the frequency of scorpion stings in the Phoenix, Arizona, metropolitan area. Landsc Urban Plan 1999; 45:47-55. 
7. Nodari FR, Leite ML, Nascimento E. Aspectos demográficos, espaciais e temporais dos acidentes escorpiônicos ocorridos na área de abrangência da 3 a Regional de Saúde - Ponta Grossa, PR, no período de 2001 a 2004. Publicatio UEPG: Ciências Biológicas e da Saúde 2006; 12:15-26.

8. Nunes CS, Bevilacqua PD, Jardim CCG. Aspectos demográficos e espaciais dos acidentes escorpiônicos no Distrito Sanitário Noroeste, Município de Belo Horizonte, Minas Gerais, 1993 a 1996. Cad Saúde Pública 2000; 16:213-23.

9. Campolina D. Georreferenciamento e estudo clínico-epidemiológico dos acidentes escorpiônicos atendidos em Belo Horizonte, no Serviço de Toxicologia de Minas Gerais [Dissertação de Mestrado]. Belo Horizonte: Universidade Federal de Minas Gerais; 2006.

10. Prefeitura Municipal de Ponta Grossa. Plano diretor participativo. http://www.pg.pr.gov.br/planodiretor (acessado em 04/Nov/2011)

11. Rouquayrol MZ, Almeida Filho N. Epidemiologia \& saúde. 5ạ Ed. Rio de Janeiro: UNIFOR; 1999.

12. Santos SM, Souza WV, organizadores. Introdução à estatística espacial para a saúde publica. Brasília: Ministério da Saúde; 2007. (Série B. Textos básicos de Saúde). (Série Capacitação e Atualização em Geoprocessamento em Saúde, 3).

13. Vieira S. Bioestatística: tópicos avançados. 2a Ed. Rio de Janeiro: Elsevier; 2004.

14. Chippaux JP, Goyffon M. Epidemiology of scorpionism: a global appraisal. Acta Trop 2008; 107:71-9.

15. Gómez JP, Otero R. Ecoepidemiología de los escorpiones de importancia médica en Colombia. Rev Fac Nac Salud Pública 2007; 25:50-60.

16. Lourenço WR, Cuellar O. Scorpions, scorpionism, life history strategies and parthenogenesis. JVenom Anim Toxins 1995; 1:51-62.
17. Mineo MF, Franco-Assim GA, Del-Claro K. Repertório comportamental do escorpião amarelo Tityus serrulatus Lutz \& Mello 1922 (Scorpiones, Buthidae) em cativeiro. Revista Brasileira de Zoociências 2003; 5:23-31.

18. Lira-da-Silva RM, Amorim AM, Carvalho FM, Brazil TK. Acidentes por escorpião na Cidade do Salvador, Bahia, Brasil (1982-2000). Gaz Méd Bahia 2009; 79 Suppl 1:43-9.

19. Bailey TC, Gatrell AC. Interactive spatial data analysis. Essex: Longman Scientific \& Technical; 1995.

20. Veloso IF, Cunha MCM, Pessanha JEM, Almeida MCM, Morais MHF. Geoprocessamento na avaliação, planejamento e gerenciamento no controle de doenças transmitidas por vetores e de agravos humanos envolvendo animais. Rev Bras Epidemiol 2002; 5(Esp.):48.

21. Soares MRM, Azevedo CS, De Maria M. Escorpionismo em Belo Horizonte, MG: um estudo retrospectivo. Rev Soc Bras Med Trop 2002; 35:359-63.

22. Szilagyi VJ, Voltolini JC, Fernandes AL, Castagna CL. Distribuição espacial de indivíduos adultos e juvenis de escorpiões Tityus serrulatus e Tityus bahiensis (Buthidae) em ambiente urbano, Campinas, SP. In: Anais do VIII Congresso de Ecologia do Brasil. Caxambu: Sociedade de Ecologia do Brasil; 2007. p. 1-2.

23. Kaltsas D, Mylonas M. Locomotory activity and orientation of Mesobuthus gibbosus (Scorpiones: Buthidae) in central Aegean Archipelago. Journal of Natural History 2010; 44:1445-59.

24. Spirandeli-Cruz EFS, Yassuda CRW, Barraviera JJ. Programa de controle de surto de escorpião Tityus serrulatus, Lutz e Mello 1922, no Município de Aparecida, São Paulo. Rev Soc Bras Med Trop 1995; 28:123-8.

Recebido em 04/Abr/2012

Versão final reapresentada em 24/Dez/2012

Aprovado em 08/Abr/2013 